\title{
From killer to carer: steroid hormones and paternal behaviour
}

\author{
Ruan de Bruin ${ }^{1 *}$, Andre Ganswindt ${ }^{2}$ and Aliza le Roux ${ }^{1}$ \\ ${ }^{1}$ Mammalian Cognition Research Group, Department of Zoology and Entomology, University of the \\ Free State, Qwaqwa campus, Phuthaditjhaba, South Africa \\ ${ }^{2}$ Department of Anatomy and Physiology, Faculty of Veterinary Science, University of Pretoria, \\ Onderstepoort, South Africa \\ *Corresponding author, email: ruandb@hotmail.com
}

\section{Abstract}

Mammalian parental investment (i.e., care of descendant offspring) is largely biased towards maternal contributions due to the specific feeding needs of mammalian offspring; however, varying degrees of paternal investment have been reported in about $10 \%$ of all mammalian species. Within the order Carnivora, paternal contribution to rearing offspring is particularly high: an estimated $32 \%$ of all studied carnivore species exhibit direct paternal care. Despite the prominence of paternal investment in carnivores, the endocrine basis of this behaviour is not well understood. This review examines the current - highly constrained -- state of knowledge about the endocrine basis of carnivore paternal investment. We attempt to link changes in androgen and glucocorticoid levels with variation in direct and indirect paternal care behaviour making specific predictions regarding the way forward. Well studied species such as bat-eared foxes (Otocyon megalotis), dwarf mongoose (Helogale parvula) and meerkats (Suricata suricatta), where social dynamics are relatively well understood, can act as ideal model systems through which we may further investigate the endocrine basis of paternal investment in carnivores.

Key words: Androgens; Carnivore; Glucocorticoids; Paternal investment. 


\section{Introduction}

Mammalian parental investment is often heavily skewed towards maternal care, with young dependent on maternal milk for survival (Nowak et al. 2000). However, in 5 $10 \%$ of mammal species, males also greatly invest in post-natal infant care (Woodroffe and Vincent 1994). The concept of paternal investment is by no means novel and has been extensively described for various taxa such as fish, amphibians and birds (Ridley 1978; Schneider and Lamprecht 1990; Ketterson and Nolan Jr 1994; Smith and Wootton 1995; Beck 1998; Møller and Cuervo 2000; Balshine 2012). Over the past 30 years more work has been focussing on the role male mammals play in raising and caring for their offspring, predominantly in rodents, primates and carnivores (Kleiman and Malcolm 1981; Dewsbury 1985; Wright 1990; Brown 1993; Woodroffe and Vincent 1994; Jones and Wynne-Edwards 2001).

In contrast to maternal contribution where the roles of different hormones are relatively well understood and defined (Zarrow et al. 1971; Bridges et al. 1990; Rosenblatt 2002), little is known about the regulative role of hormones in the case of paternal contribution. The regulative hormones involved in paternal care have been extensively studied in non-mammalian taxa (Eisner 1960; Townsend and Moger 1987; Wingfield et al. 1990; Buntin et al. 1991; Knapp et al. 1999; Páll et al. 2002; Lynn 2008) and even though these findings provide a basis for general predictions in mammals, conclusions cannot be drawn a priori without supporting evidence. Some experiments have been conducted to unravel the role of each hormone in terms of paternal investment in mammals, particularly rodents and primates; however, reports on larger mammals - especially carnivores - are extremely scarce and remain mostly correlative with a lack of experimental support (Wynne-Edwards and Reburn 2000). In carnivores, the paucity of data on paternal hormones is further exacerbated by the confounding behavioural changes that most males undergo during the breeding season: indirect parental care (such as territorial defence) and direct care (such as grooming) are expected to have diametrically opposite endocrinological drivers.

The purpose of this review is not to identify paternal investment in carnivores (reviewed by Kleiman and Malcolm 1981), but rather to highlight the skewed research focus in carnivore studies, which under-values the unique opportunity to describe paternal care from a mechanistic perspective (Table 1). Importantly, the 
Table 1: Summary of existing research reporting on endocrine changes in carnivore species with known paternal investment. All the literature published during the last 20 years (Research effort) indicates that it is not due to a lack of research on each species that there are no reports on steroid hormones for the majority of carnivore species. The table was adjusted from Kleiman and Malcolm (1981). ScienceDirect was used to do the literature search. Articles were chosen for the table when the name of the species appeared in the title, abstract and/or keywords of the scientific manuscript. '-' No known reports on steroid hormone for the species

\begin{tabular}{|c|c|c|}
\hline Species & Reports on endocrine response & Research effort \\
\hline \multicolumn{3}{|l|}{ Canidae } \\
\hline Canis lupus & $\begin{array}{l}\text { Asa and Valdespino (1998), } \\
\text { Sands and Creel (2004) }\end{array}$ & 338 \\
\hline Canis latrans & Asa and Valdespino (1998) & 88 \\
\hline Canis aureus & Asa and Valdespino (1998) & 54 \\
\hline Canis mesomelas & Asa and Valdespino (1998) & 16 \\
\hline Canis simensis & van Kesteren et al. (2012) & 4 \\
\hline Lycaon pictus & Creel et al. (1996) & 37 \\
\hline Cuon alpinus & - & 11 \\
\hline Alopex lagopus & - & 65 \\
\hline Vulpes vulpes & Maurel and Boissin (1981) & 392 \\
\hline Vulpes velox & - & 8 \\
\hline Vulpes corsac & - & 4 \\
\hline Vulpes zerda & - & 4 \\
\hline Nyctereutes procyonoides & - & 39 \\
\hline Otocyon megalotis & - & 8 \\
\hline Dusicyon culpaeus & - & 3 \\
\hline Dusicyon griseus & - & 1 \\
\hline Cerdocyon thous & - & 23 \\
\hline Speothos venaticus & - & 10 \\
\hline Chrysocyon brachyurus & - & 22 \\
\hline Procyonidae & - & \\
\hline Bassariscus astutus & - & 3 \\
\hline Ailurus fulgens & - & 15 \\
\hline \multicolumn{3}{|l|}{ Mustelidae } \\
\hline Mustela erminea & - & 28 \\
\hline Mustela nivalis & - & 18 \\
\hline Mustela rixosa & - & 1 \\
\hline Mustela putorius & - & 139 \\
\hline Mustela lutreola & - & 17 \\
\hline Martes martes & - & 207 \\
\hline Martes americana & - & 19 \\
\hline Gulo gulo & - & 104 \\
\hline Eira barbara & - & 3 \\
\hline Meles meles & Woodroffe et al. $(1995,1997)$ & 248 \\
\hline Arctonyx collaris & - & 2 \\
\hline Lutra lutra & - & 82 \\
\hline Lutra canadensis & - & 4 \\
\hline Lutra maculicollis & - & 3 \\
\hline Lutrogale perspicillata & - & 2 \\
\hline Aonyx cinereus & - & 1 \\
\hline Pteronura brasiliensis & - & 5 \\
\hline \multicolumn{3}{|l|}{ Viverridae } \\
\hline Civettictis civetta & - & 2 \\
\hline Arctictis binturong & - & 2 \\
\hline Fossa fossa & - & 3 \\
\hline Galidia elegans & - & 0 \\
\hline Galidictis fasciata & - & 0 \\
\hline Mungotictis decemlineata & - & 0 \\
\hline Salanoia concolor & - & 0 \\
\hline Herpestes pulverulentus & - & 0 \\
\hline Herpestes sanguineus & - & 0 \\
\hline Mungos mungos & - & 132 \\
\hline Helogale parvula & Creel et al. $(1992,1993)$ & 7 \\
\hline Suricata suricatta & $\begin{array}{c}\text { Young et al. (2004), } \\
\text { Carlson et al. (2004, 2006a, 2006b) }\end{array}$ & 51 \\
\hline Hyaena hyaena & 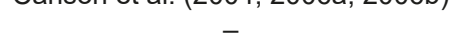 & 261 \\
\hline Hyaena brunnea & - & 10 \\
\hline Crocuta crocuta & - & 125 \\
\hline Proteles cristatus & Marneweck et al. (2015) & 3 \\
\hline
\end{tabular}




\begin{tabular}{lcc}
\hline Species & Reports on endocrine response & Research effort \\
\hline Felidae & & 23 \\
Felis silvestris & - & 2 \\
Felis silvestris lybica & - & 6 \\
Felis nigripes & - & 6 \\
Felis serval & - & 3 \\
Prionailurus viverrinus & - & 6 \\
Felis bengalensis & - & 1 \\
Felis aurata & - & 0 \\
Catopuma temminckii & - & 20 \\
Felis concolor & - & 3 \\
Felis geoffroyi & - & 2 \\
Felis yagouaroundi & - & 267 \\
Lynx lynx & - & 131 \\
Panthera leo & - & 92 \\
Panthera tigris & - & 76 \\
Panthera pardus & - & 0 \\
Uricia unicia & - & 11 \\
Neofelis nebulosa & & 2 \\
\hline
\end{tabular}


need to protect territories and mates from rival males will allow us to examine the endocrine correlates of increased intra-specific aggression concurrently with increased demands for caring behaviour. For the purpose of this review, we mainly focus our report on steroid hormones (androgens and glucocorticoids) as these data can be obtained non-invasively through the use of faeces as hormone matrix. In this review it is surprising to see how few studies actually used faecal samples for their endocrine analysis, highlighting major opportunities that are not being utilised.

Kleiman and Malcolm (1981) defined paternal investment as “...any increase in a prereproductive mammal's fitness attributable to the presence or action of a male". In this review we use their definition of paternal investment and include the behaviour of all males in a social group and not only the breeding male, as nonpaternal male group members are often involved in caring for the young. We use paternal investment, paternal care and paternal effort interchangeably throughout this manuscript.

\section{Carnivore Biology}

In carnivores, social systems range from solitary to highly social, with monogamous pairs reported for most of the canids (Kleiman 1977; Macdonald 1983). It is difficult to pinpoint a shared, ancestral social system for all carnivores, as different foraging niches result in distinct evolutionary pressures. In the case of felids, a solitary existence seems to have given rise to the sociality observed between mothers and their offspring and the strong social bonds in lion (Panthera leo) prides (Kleiman and Eisenberg 1973). In contrast, the long-term pair association common in canids suggest that sociality might have been the ancestral trait for this family (Kleiman and Eisenberg 1973). Within the Carnivora, there is significant intra-specific variability in

social systems, with even solitary species being temporarily social during the breeding season (Macdonald 1983; Barber and Lindzey 1986). Such a wide range of social systems opens the door for numerous questions on the mechanistic basis of male social and caring behaviour.

There are two primary ways in which male carnivores care for related or descendant young: the first is as part of a cooperatively breeding family group. A number of carnivore species form extended family groups, where young are philopatric and help raise the next generation (Harrison and Harrison 1984; 
Moehlman 1987; Bryan et al. 2006; Nichols et al. 2012). Cooperative breeding is an evolutionary trait found in socially monogamous species where most of the group members are closely related (Lukas and Clutton-Brock 2012). The benefits of familygroup living are not restricted to increased offspring survival, but also include greater opportunities to find and protect food resources, and increased predator awareness (Hector 1986; Boesch 1994; Creel and Creel 1995; Clutton-Brock et al. 1999). Another advantage for staying with the natal group is the possibility of inheriting a territory from the parents, becoming the dominant breeding individual. In red foxes (Vulpes vulpes), philopatric offspring not only had higher survival rates, but they succeeded in becoming the dominant breeders, producing more young than their dispersing counterparts (Baker et al. 1998). Being allowed in the natal territory help individuals gain valuable experience in a well-known habitat and learn parenting skills, while increasing current pup survival (Moehlman 1987).

The second common strategy is where male carnivores care for their offspring as part of a monogamously bonded pair. As is the case with other taxa, monogamous carnivore pairs typically exhibit bi-parental care, and the need for paternal contributions is typically vital to successful reproduction in such species (Trivers 1972; Moehlman 1987; Queller 1997; Wright et al. 2010; Lukas and CluttonBrock 2012). For example, in monogamous bat-eared foxes (Otocyon megalotis), more pups ultimately survive to dispersal age when the male is involved in the parental duties (Wright 2006); although there have been reports of a single female successfully raising pups (Maas 1993 as referenced in Wright 2006). In aardwolves (Proteles cristatus), another socially monogamous carnivore, males also rigorously protect their offspring by chasing away potential predators approaching their dens (Richardson 1987).

Reproductive fitness consequences are likely to affect the level of paternal investment: paternity certainty (in monogamous pairs), and degree of relatedness (in cooperative breeders) should impact the quality of male care. Though extra-pair copulation is rare amongst socially monogamous carnivores (Wright et al. 2010), it is not uncommon in solitary species and species living in large social groups (SilleroZubiri et al. 1996; Young et al. 2007). When extra-pair copulations occur, it is not in the best interest of the male to invest in the young fathered by another male. This holds true for aardwolves, in which mate abandonment (by the male) was observed 
after a female mated with a neighbouring male (Richardson and Coetzee 1988). Inclusive fitness arguments thus suggest we should expect to see paternal care predominantly in cooperative helpers and pair-bonded species.

\section{Paternal Investment}

Paternal investment can take on many forms and is not limited to behaviour that directly involves the offspring, but constitutes a number of behavioural actions that can be interpreted as either indirect or direct male care (Kleiman 1977). Indirect paternal effort is any behaviour that is performed in the absence of the young, but ultimately contributes to their enhanced survival (Kleiman and Malcolm 1981; Rosenblatt 2002). Thus, patrolling territorial boundaries, defending resources and female provisioning are considered indirect paternal effort (Kleiman and Malcolm 1981; Macdonald 1983). Indirect paternal investment is not often considered "paternal care" as it is challenging to quantify a specific behaviour as solely paternal. As a result, reports on indirect male care are limited, or classified together with direct male care, making it difficult to assess the hormones associated with this type of paternal investment.

The most obvious form of indirect paternal investment is patrolling territory boundaries and fending off rival males (Macdonald 1983; Sillero-Zubiri and Macdonald 1998; Müller and Manser 2007). Males who are unsuccessful in this venture not only forego future breeding opportunities but also immediately suffer reduced reproductive success as a result of non-parental infanticide (Bellemain et al. 2006). Giant river otters (Pteronura brasiliensis) are monogamous breeders with frequent male investment from group members (Rosas et al. 2009). However, the breeding male is generally not very involved with his offspring immediately postpartum, but spends a substantial amount of time vocalising and patrolling territory boundaries in an attempt to deter intruders (Londoño and Muñoz 2006). Even though this report was based on a single, captive population it clearly highlights indirect male investment in a pair-bonded species. Larger groups (i.e., more helpers) of Ethiopian wolves (Canis simensis) are more successful in defending their territories from intruders compared to smaller packs (Sillero-Zubiri and Macdonald 1998). Territorial defence is usually associated with aggressive interactions, which are not conducive to the caring (grooming or huddling) behaviour usually associated with 
paternal investment. Males might therefore experience a possible behavioural and endocrinological trade-off between defending their territories and caring for their offspring.

Another important form of indirect paternal care is female provisioning. There are different ways in which a male can provide food to the female: he can either bring whole food items back to the den, or regurgitate ingested food which the female then consumes (Mech 1999, 2000). Breeding male wolves (C. lupus) regurgitate more food to the breeding female than to other group members (Mech et al. 1999). During the first several weeks post-partum, the dominant male is also continually bringing food items back to the den for the lactating female (Mech 1999, 2000). Naturally, while provisioning the female, an individual male cannot simultaneously feed the pups. Therefore, this form of indirect care is typically limited to the period while offspring are dependent on maternal milk for sustenance; once they can digest solid food, males (and/or helpers) switch to direct provisioning of the offspring.

In contrast to indirect investment, direct paternal care encompasses all behaviour that directly involves the offspring, affecting their immediate survival (Kleiman and Malcolm 1981; Balshine 2012). Because of the direct pup-parent interactions, it is easier to recognise direct paternal investment as parental care, and most of the reports in the available literature focus on direct paternal investment (Kleiman and Malcolm 1981). Direct paternal investment, including food provisioning, teaching and grooming, has been reported for $22 \%$ of all carnivore species studied (Adapted from Kleiman and Malcolm 1981; Bekoffet al. 1984).

Food provisioning to offspring can be considered the most direct and frequently observed form of paternal investment. Male free-ranging dogs ( $C$. familiaris) frequently regurgitate food for pups especially during the time when the female starts to reduce her contact with the young (Pal 2005). In group-living wolves, all members of the family group regurgitate more to pups than to other group members (Mech et al. 1999). Adults can also provide live prey for the young in order to learn valuable hunting techniques; behaviour that is frequently observed in carnivores (Moehlman 1987; Pauw 2000). Male bat-eared foxes and meerkats (Suricata suricatta) have been reported presenting live prey to their young (Thornton 
and McAuliffe 2006; le Roux et al. 2014). During these presentations, the pups explore various handling techniques and learn the best way of ingesting several prey items (Thornton 2008). Provisioning of live prey does come at a cost to the adults involved as they might need to retrieve lost prey, reducing their available foraging time (Doolan and Macdonald 1999; Thornton and McAuliffe 2006).

Direct paternal investment also includes playing with young. Playing creates new learning opportunities and allows offspring to prepare for unexpected situations later in life (Biben 1982; Spinka et al. 2001). Play behaviour, however, is poorly understood and a functional explanation for the evolution of this behaviour remains elusive (Sharpe 2005). Nevertheless, play is regularly observed in carnivores and is assumed to help with learning (Biben 1982). Playing with the young is not restricted to the breeding male, but all group members can actively partake in playing with the offspring. Male coatis (Nasua narica), for example, can be very tolerant towards young, indulging in play behaviour such as chasing, tackling and play-fighting (Logan and Longino 2013). From the perspective of the adult, play time likely reduces foraging and resting time.

Other direct forms of paternal investment include seeing to the physical needs of the young such as grooming and huddling. Huddling keeps the young warm during cold nights when temperatures might fall below freezing (Doolan and Macdonald 1997). Grooming does not only have important hygienic benefits for the groomed individual, but it aids the maintenance of social bonds in family groups. In bat-eared foxes, the males are more actively involved in grooming the pups compared to the females (Lamprecht 1979; Pauw 2000). In most carnivore species huddling and grooming as a form of paternal investment has not been reported; however, it has been described in many captive carnivores (Kleiman and Malcolm 1981). It thus seems likely that social carnivores should exhibit this behaviour in the wild.

Finally, males may invest energy into ensuring the safety of their offspring. Field observations of wild bat-eared foxes showed that males actively help move pups between different den sites if there is danger around or if the group moves (Lamprecht 1979). When pups are still too small to forage with the group, certain group members will stay behind and babysit the young at the den, protecting them from predators (Doolan and Macdonald 1997; Rosas et al. 2009). In group-living 
dwarf mongoose (Helogale parvula) subordinate group members continuously remain at the den site with the young, protecting them while the rest of the group forages (Rood 1978).

The 1981 review by Kleiman and Malcolm of paternal investment in mammals was based largely on information gleaned from captive populations, and in the intervening time surprisingly little data have been added to the literature on paternal investment in male carnivores. The detailed descriptions of paternal investment in wild carnivores have been limited to a few species such as bat-eared foxes (Lamprecht 1979; Pauw 2000; Wright 2006). Considering the relatively large number of carnivore species in which paternal investment is known, we are presented with numerous opportunities and challenges in the study of mammalian parenting behaviour. We propose that an excellent starting point will be to elucidate the mechanistic causes and consequence of paternal care in carnivores, utilizing steroid hormones that can be readily obtained from faecal matter.

\section{Steroid hormones and Paternal investment}

We were able to find only two papers explicitly investigating the link between carnivore paternal care and hormonal changes - companion studies on wild meerkats (Carlson et al. 2006a, 2006b). Most endocrinological studies remain correlative, where changes in hormone levels are related to periods of offspring dependence (Catling 1979; Asa and Valdespino 1998; Sands and Creel 2004; Creel 2005; Minter and DeLiberto 2008; Marneweck et al. 2015).

\section{Androgens}

Testosterone is a key androgen predominantly secreted by the testes; playing a major role in the expression of aggressive and reproductive behaviour and the development of secondary male sex characteristics (Baum 2002; Hau 2007). Androgen secretion is primarily controlled by the hypothalamic-pituitary-gonadal (HPG) axis. The pituitary gland secretes follicle-stimulating hormone and luteinizing hormone, which in turn stimulate sperm production and maintenance of the secondary male characteristics like antlers and the mane of a lion (Campbell and Reece 2005). It is important to note however, the interacting relationship between the HPG axis and the hypothalamic-pituitary-adrenal (HPA) axis, controlling the 
secretion of glucocorticoids. Experimental evidence in male rats suggests a regulatory link between the HPG and HPA axes where increased HPG activity suppresses the HPA and vice versa (Monder et al. 1994; Viau and Meaney 2004); however, in other species there does not seem to be such a strong regulatory response (Bercovitch and Clarke 1995; Robbins and Czekala 1997; Strier et al. 1999).

\section{Androgens and Paternal investment}

Across all mammalian taxa, it is suggested that males with comparatively higher androgen levels are more aggressive and subsequently triumph over males with lower levels during competitive interactions (Creel et al. 1993; Cavigelli and Pereira 2000; Preston et al. 2003). These victories allow the dominant male to procure better territories and possibly more mating opportunities (Zielinski and Vandenbergh 1993; van Kesteren et al. 2012). This hypothesis has been experimentally tested in rodents, but for larger species the predictions are based mainly on field observations (Zielinski and Vandenbergh 1993).

In a system where paternal investment is essential to maximise reproductive fitness, androgen concentrations are expected to remain low. The increased level of aggression associated with high androgen concentrations might be detrimental to high quality paternal care (Wingfield et al. 1990; Gromov and Osadchuk 2015). In carnivores, this idea is supported by a few studies where the dispersing (non-caring) males have higher androgen concentrations than their resident counterparts. High serum androgen levels have been correlated with increased dispersing behaviour of male European badgers (Meles meles) (Woodroffe et al. 1995; Woodroffe et al. 1997). Immigrant males of this species showed higher androgen levels and fathered more offspring than the residential males in the territory (Woodroffe et al. 1995; Woodroffe et al. 1997). European badgers express both direct and indirect paternal investment (Kleiman and Malcolm 1981); however, Woodroffe and colleagues did not report any paternal care during their studies. Male dwarf mongoose floating between family groups also experienced higher androgen concentrations than residential or newly settled males (Creel et al. 1993). Although immigration led to higher aggression rates between males, males who successfully entered a new 
group subsequently had lower androgen concentrations than floater males (Creel et al. 1993).

There are multiple challenges in correlating androgens with paternal behavioural. Firstly, the few studies that exist do not show similar seasonal changes in androgen concentrations. Male coyotes ( $C$. latrans) experienced a peak in serum androgen concentrations coinciding with the height of the breeding season (Minter and DeLiberto 2008). Similar to coyotes, male dingos (C. f. dingo) had the highest serum androgen concentration during the peak breeding season, with androgen levels decreasing after this period (Catling 1979). However, the breeding season also coincides with other behavioural changes such as increased territorial defence (e.g., yellow mongoose - (le Roux et al. 2008)), which is considered indirect paternal care. This rise in aggressive behaviour may, therefore, be the more prominent driver of androgen concentrations.

Where direct care is explicitly assessed, no variation in androgen concentrations becomes apparent. A comparison of urinary androgen levels between the dominant male dwarf mongoose and his subordinates revealed indistinguishable profiles for the two classes (Creel et al. 1992). Despite the absence of a seasonal change in androgen levels, all males were still invested in caring for the young in the group (Rood 1978; Creel et al. 1993). Plasma androgen concentration was also unaffected by the amount of time male meerkat helpers spend feeding offspring in their family groups (Carlson et al. 2006b). These reports highlight the possibility of direct paternal care not being under strict androgen control for these two mongoose species (Creel et al. 1992; Moss et al. 2001; Carlson et al. 2006b).

For some carnivores, the period of direct pup care is separate from the season when high androgen levels are advantageous for competitive reasons. In aardwolf, faecal androgen metabolite levels peaked during the dry season when successful mating was the main objective (Marneweck et al. 2015). During the wet season the male is involved in raising his pups (Richardson 1987); it may be that decreased androgen concentrations during this time facilitated the expression of paternal behaviour for this species. Marneweck et al. (2015) did not directly investigate the expression of paternal investment, thus further investigation is 
necessary with a more specific research question pertaining to the level of paternal investment for the species.

In carnivores, androgen concentrations might be more critical for the expression of indirect paternal behaviour than for direct male investment. In most rodents, higher androgens are important for the expression of direct paternal investment (Trainor and Marler 2001; Saltzman and Ziegler 2014; Gromov and Osadchuk 2015; Martínez et al. 2015) with some exceptions (Hume and WynneEdwards 2005; Gromov and Osadchuk 2015). To our knowledge, paternal experience has not been considered as a factor influencing androgen secretion in rodents. In primates, it is suggested that lower androgen levels are important for the expression of direct paternal investment, but paternal experience has been found to also be an important factor affecting androgen concentrations (Nunes et al. 2000; Nunes et al. 2001; Rafacz et al. 2012). Correlative findings from limited carnivore studies are inconclusive, as some report a positive association of androgens with direct paternal investment and others indicate a negative association

A possible method for unravelling the regulatory role of androgens in the expression of the two forms of paternal investment is to study males who vary in direct investment, but have similar roles in terms of indirect investment. Such conditions could be present in cooperative breeders. For example, both breeding and non-breeding male meerkats are involved in defending the territory from intruders, but the breeding male does not associate with, or provision his offspring as much as the non-breeding group members (Doolan and Macdonald 1999; Kutsukake and Clutton-Brock 2010). Such an approach could, theoretically, help determine the endocrine changes associated with the different forms of paternal investment by comparing androgen concentrations between the different male classes within the same family group. If androgen levels were indeed not a major factor regulating direct paternal investment, it would set carnivores apart from their rodent and primate counterparts and also suggest a more powerful regulatory role of other hormones (e.g., prolactin) in the expression of direct paternal behaviour for this family. 


\section{Glucocorticoids}

Glucocorticoids are another vital class of steroid hormones that may regulate paternal care, as paternal investment could be altered in males perceiving stressors over a prolonged period of time. Animals experience stress when there is a disruption of homeostasis; this is then followed by a series of adaptive mechanisms aimed at protecting the individual and restoring homeostasis (Tilbrook et al. 2000; Nelson 2005). Stressors can be anything from environmental alterations, e.g., extreme temperatures (Nelson 2005; Gesquiere et al. 2008); physiological changes, such as limited water intake (Millspaugh et al. 2001; Nelson 2005); or social factors, which includes competitive interactions between individuals (Nelson 2005; Zav'ialov et al. 2012). A stress stimulus causes increased secretion of corticotropin-releasing hormone, which in turn stimulates the secretion of adrenocorticotropic hormone (ACTH). Increased ACTH levels stimulate the secretion of glucocorticoids, changing the metabolic activity of the target cells as part of the stress response. Cortisol and corticosterone are the primary glucocorticoids secreted by the mammalian adrenal glands. Whereas a regulated temporary stress response might save an individual from a potentially harmful situation, chronically elevated glucocorticoid levels can have a negative effect on survival and reproduction processes (Creel 2001; Carlson et al. 2004; Sands and Creel 2004; Barja et al. 2008; van Kesteren et al. 2012; Creel et al. 2013a; Creel et al. 2013b).

One of the major draw-backs of the current literature reporting on glucocorticoid concentrations in carnivores is the bias towards socially-gregarious species. In these species social status is a major driving force influencing changes in glucocorticoid levels, whereas the relationship between these hormones and the expression of paternal behaviour is seldom considered. Social instability is often thought to be responsible for variation in glucocorticoid levels, as higher ranking males might encounter more aggressive interactions to maintain their status and breeding opportunities (Creel et al. 1996; McLeod et al. 1996). This is evident in African wild dogs (Lycaon pictus) where dominant animals are involved in significantly more aggressive encounters during the breeding season compared to subordinates (Creel 2005). Because many species use aggressive encounters to assert their dominance it is suggested that glucocorticoid concentrations are higher in the dominant breeding animals (meerkats - (Carlson et al. 2004); wolves - (Sands 
and Creel 2004); Iberian wolves (C. I. signatus) - (Barja et al. 2008); Ethiopian wolves - (van Kesteren et al. 2012); reviewed in (Creel et al. 2013b)). In light of the different social dynamics, when considering paternal care a more complex picture regarding glucocorticoid concentration emerges.

\section{Glucocorticoids and Paternal investment}

In cooperative breeding meerkats, all group members are invested in caring and providing for the pups in the group (Carlson et al. 2006a, 2006b). Helper males often stay behind at the den babysitting rather than going out to forage with the group (Carlson et al. 2006a). During this study, Carlson and colleagues concluded that males who babysat had lower serum glucocorticoid levels than males who set off to forage for the day. Conversely, a companion study investigating pup provisioning and associated endocrine changes suggested that serum glucocorticoid levels were positively associated with pup provisioning (Carlson et al. 2006b). Such detailed investigations into the endocrinology of paternal care in wild carnivores are rare, however.

We may cautiously use season as a proxy for changes in paternal investment, and gauge how glucocorticoids change with the presence of dependent young. Results from such studies are somewhat contradictory. Breeding male wolves had higher faecal glucocorticoid metabolite concentrations during the breeding season than the non-breeding season, when there are no pups present (Sands and Creel 2004). Unlike wolves, male aardwolves exhibited no differences in faecal glucocorticoid metabolite concentrations between the breeding and non-breeding seasons (Marneweck et al. 2015). Male aardwolves are heavily involved in raising their pups and further investigation into their paternal investment might yield valuable insight into the endocrine correlates of this behaviour (Richardson 1987).

From the very limited existing evidence, it appears as if male carnivores may experience elevated glucocorticoids while rearing offspring. In rodents, the general trend appears to be that glucocorticoid levels do not have an adverse effect on the expression of paternal behaviour (Bales et al. 2006; Chauke et al. 2011; Harris et al. 2011; Harris et al. 2013; Saltzman and Ziegler 2014). In primates, the picture is more complicated, with glucocorticoids being either higher (common marmosets (Callithrix jacchus) - (da Silva Mota et al. 2006)) or lower (tufted-ear marmosets (C. kuhlii) - 
(Nunes et al. 2001)) in males involved in paternal care. Even though there was no difference in glucocorticoid levels for experienced and inexperienced cotton-top tamarin (Saguinus oedipus) fathers pre-partum, both male classes experienced an increase in glucocorticoid concentration following cues from their mate (Ziegler and Snowdon 2000; Ziegler et al. 2004). We were unable to find studies reporting the effect of paternal experience on glucocorticoid levels for rodents.

\section{Conclusion}

Based on the limited data currently available, we highlight some ways in which carnivores share endocrine responses with other paternal mammals, and also a few ways in which they appear to be distinct. We predict a similar trend in carnivore paternal investment to that reported for primates (Nunes et al. 2000; Nunes et al. 2001). Specifically, lower androgen concentrations will be an important predictor for the expression of direct parental investment in male carnivores. This could be confirmed by looking at paternal care in species where the degree of investment differs between the sire and helper males. Comparing androgen levels between each social class and relating the endocrine difference to differences in paternal care will give us a better understanding of the role androgens play in the expression of carnivore paternal care. In terms of glucocorticoid concentrations, we predict that unlike rodents, glucocorticoid levels might be an important factor in regulating direct paternal investment in carnivores. It is important to consider the social structure of the species when assessing paternal care. Other factors that need to be considered when investigating the endocrine basis of paternal investment are prior experience and the interaction between the HPG and HPA axes. Reproductive experience might be especially important in species where a single male produces offspring across many breeding seasons, a phenomenon commonly seen amongst carnivores.

In order to fully understand the endocrine basis of paternal investment, we suggest focussing on well-studied species such as wolves, African wild dogs and cooperatively breeding mongoose species. However, this may only offer the opportunity to contrast sires with male helpers, within a cooperatively breeding social system. Monogamous species with high levels of paternal investment, such as aardwolves and bat-eared foxes, offer further opportunities for study, offering contrasting points to cooperative breeders. Offspring demands on these 
monogamous males are probably significantly higher, skewing their behavioural efforts towards care rather than territory defence or maintenance of dominance rank. Long-term research projects on these species could make it easier to collect behavioural data on the expression of paternal investment by both the sires and helper males.

It is relatively easy to conduct endocrine comparisons between breeding and non-breeding males by using faecal samples, a technique that can be used for captive and wild populations and present relatively low risk to the animals and scientists (Monfort et al. 1998; Young et al. 2004; Schwarzenberger 2007). Being completely non-invasive, any hormone fluctuations associated with trapping and handling of study animals in order to collect blood samples will be eliminated. Carnivores exhibiting significant inter- and intra-specific variation in social systems, yet a high degree of male parental investment provide an ideal opportunity for investigating male behaviour in the context of caring for offspring. Carnivores also provide the opportunity to compare the possible trade-off between direct and indirect paternal investment, particularly from the mechanistic point of view.

\section{Acknowledgment}

The authors would like to thank $\mathrm{Dr} S$. Periquet and $\mathrm{Dr}$ F. Dalerum for their constructive comments that helped to improve the manuscript. P.R de Bruin would like to thank the South African National Research Foundation (NRF) and the University of the Free State for their financial support while writing this manuscript.

\section{References}

Asa CS, Valdespino C. 1998. Canid reproductive biology: an integration of proximate mechanisms and ultimate causes. American Zoologist 38: 251-259.

Baker PJ, Robertson CP, Funk SM, Harris S. 1998. Potential fitness benefits of group living in the red fox, Vulpes vulpes. Animal Behaviour 56: 1411-1424.

Bales KL, Kramer KM, Lewis-Reese AD, Carter CS. 2006. Effects of stress on parental care are sexually dimorphic in prairie voles. Physiology \& behavior 87: 424-429. 
Balshine S. 2012. Patterns of parental care in vertebrates. The Evolution of Parental Care: 62-80.

Barber KR, Lindzey FG. 1986. Breeding behavior of black bears. Pp. 129-136 in Bears: Their Biology and Management.

Barja I, Silván G, Illera JC. 2008. Relationships between sex and stress hormone levels in feces and marking behavior in a wild population of Iberian wolves (Canis lupus signatus). Journal of Chemical Ecology 34: 697-701.

Baum M. 2002. Neuroendocrinology of sexual behavior in the male. Behavioral Endocrinology 2: 153-204.

Beck CW. 1998. Mode of fertilization and parental care in anurans. Animal Behaviour 55: 439-449.

Bellemain E, Swenson JE, Taberlet P. 2006. Mating Strategies in Relation to Sexually Selected Infanticide in a Non-Social Carnivore: the Brown Bear. Ethology 112: 238-246.

Bercovitch FB, Clarke AS. 1995. Dominance rank, cortisol concentrations, and reproductive maturation in male rhesus macaques. Physiology \& behavior 58: 215-221.

Biben M. 1982. Object play and social treatment of prey in bush dogs and crab-eating foxes. Behaviour 79: 201-211.

Boesch C. 1994. Cooperative hunting in wild chimpanzees. Animal Behaviour 48: 653-667.

Bridges RS, Numan M, Ronsheim PM, Mann PE, Lupini CE. 1990. Central prolactin infusions stimulate maternal behavior in steroid-treated, nulliparous female rats. Pp. 80038007 in Proceedings of the National Academy of Sciences.

Brown RE. 1993. Hormonal and experiential factors influencing parental behaviour in male rodents: an integrative approach. Behavioural Processes 30: 1-27.

Bryan HM, Darimont CT, Reimchen TE, Paquet PC. 2006. Early ontogenetic diet in gray wolves, Canis lupus, of coastal British Columbia. The Canadian Field-Naturalist 120: 6166.

Buntin JD, Becker GM, Ruzycki E. 1991. Facilitation of parental behavior in ring doves by systemic or intracranial injections of prolactin. Hormones and Behavior 25: 424-444.

Campbell N, Reece J. 2005. Biology, 7th ed. Pearson, Education Inc, San Francisco, CA.

Carlson AA, Young AJ, Russell AF, Bennett NC, McNeilly AS, Clutton-Brock T. 2004. Hormonal correlates of dominance in meerkats (Suricata suricatta). Hormones and Behavior 46: 141-150.

Carlson AA, Russell AF, Young AJ, Jordan NR, McNeilly AS, Parlow AF, Clutton-Brock T. 2006a. Elevated prolactin levels immediately precede decisions to babysit by male meerkat helpers. Hormones and Behavior 50: 94-100. 
Carlson AA, Manser MB, Young AJ, Russell AF, Jordan NR, McNeilly AS, Clutton-Brock T. 2006b. Cortisol levels are positively associated with pup-feeding rates in male meerkats. Proceedings of the Royal Society of London B: Biological Sciences 273: 571-577.

Catling P. 1979. Seasonal variation in plasma testosterone and the testis in captive male dingoes, Canis familiaries dingo. Australian Journal of Zoology 27: 939-944.

Cavigelli SA, Pereira ME. 2000. Mating season aggression and fecal testosterone levels in male ring-tailed lemurs (Lemur catta). Hormones and Behavior 37: 246-255.

Chauke M, Malisch JL, Robinson C, de Jong TR, Saltzman W. 2011. Effects of reproductive status on behavioral and endocrine responses to acute stress in a biparental rodent, the California mouse (Peromyscus californicus). Hormones and Behavior 60: 128-138.

Clutton-Brock T, Gaynor D, Mcllrath G, Maccoll A, Kansky R, Chadwick P, Manser M, Skinner J, Brotherton P. 1999. Predation, group size and mortality in a cooperative mongoose, Suricata suricatta. Journal of Animal Ecology 68: 672-683.

Creel S. 2001. Social dominance and stress hormones. Trends in Ecology \& Evolution 16: 491-497.

Creel S. 2005. Dominance, aggression, and glucocorticoid levels in social carnivores. Journal of Mammalogy 86: 255-264.

Creel S, Creel NM. 1995. Communal hunting and pack size in African wild dogs, Lycaon pictus. Animal Behaviour 50: 1325-1339.

Creel S, Wildt DE, Monfort SL. 1993. Aggression, reproduction, and androgens in wild dwarf mongooses: a test of the challenge hypothesis. American Naturalist: 816-825.

Creel S, Creel N, Monfort SL. 1996. Social stress and dominance. Nature 379: 212.

Creel S, Christianson D, Schuette P. 2013a. Glucocorticoid stress responses of lions in relationship to group composition, human land use, and proximity to people. Conservation Physiology 1: $\cot 021$.

Creel S, Creel N, Wildt DE, Monfort SL. 1992. Behavioural and endocrine mechanisms of reproductive suppression in Serenge dwarf mongooses. Animal Behaviour 43: 231-245.

Creel S, Dantzer B, Goymann W, Rubenstein DR. 2013b. The ecology of stress: effects of the social environment. Functional Ecology 27: 66-80.

da Silva Mota MT, Franci CR, de Sousa MBC. 2006. Hormonal changes related to paternal and alloparental care in common marmosets (Callithrix jacchus). Hormones and Behavior 49: 293-302.

Dewsbury DA. 1985. Paternal behavior in rodents. American Zoologist 25: 841-852.

Doolan S, Macdonald D. 1997. Breeding and juvenile survival among slender-tailed meerkats (Suricatu suricatta) in the south-western Kalahari: ecological and social influences. Journal of Zoology 242: 309-327. 
Doolan S, Macdonald D. 1999. Co-operative rearing by slender-tailed meerkats (Suricata suricatta) in the Southern Kalahari. Ethology 105: 851-866.

Eisner E. 1960. The relationship of hormones to the reproductive behaviour of birds, referring especially to parental behaviour: a review. Animal Behaviour 8: 155-179.

Gesquiere LR, Khan M, Shek L, Wango TL, Wango EO, Alberts SC, Altmann J. 2008. Coping with a challenging environment: effects of seasonal variability and reproductive status on glucocorticoid concentrations of female baboons (Papio cynocephalus). Hormones and Behavior 54: 410-416.

Gromov V, Osadchuk L. 2015. Parental care and testosterone secretion in forest rodent males: Sensitization and androgenic stimulation of parental behavior. Biology Bulletin 42: 354-360.

Harris BN, Perea-Rodriguez JP, Saltzman W. 2011. Acute effects of corticosterone injection on paternal behavior in California mouse (Peromyscus californicus) fathers. Hormones and Behavior 60: 666-675.

Harris BN, de Jong TR, Yang V, Saltzman W. 2013. Chronic variable stress in fathers alters paternal and social behavior but not pup development in the biparental California mouse (Peromyscus californicus). Hormones and Behavior 64: 799-811.

Harrison DJ, Harrison JA. 1984. Foods of adult Maine coyotes and their known-aged pups. The Journal of Wildlife Management: 922-926.

Hau M. 2007. Regulation of male traits by testosterone: implications for the evolution of vertebrate life histories. BioEssays 29: 133-144.

Hector DP. 1986. Cooperative hunting and its relationship to foraging success and prey size in an avian predator. Ethology 73: 247-257.

Hume JM, Wynne-Edwards KE. 2005. Castration reduces male testosterone, estradiol, and territorial aggression, but not paternal behavior in biparental dwarf hamsters (Phodopus campbelli). Hormones and Behavior 48: 303-310.

Jones JS, Wynne-Edwards KE. 2001. Paternal behaviour in biparental hamsters, Phodopus campbelli, does not require contact with the pregnant female. Animal Behaviour 62: 453464.

Ketterson ED, Nolan Jr V. 1994. Male parental behavior in birds. Annual Review of Ecology and Systematics: 601-628.

Kleiman D, Eisenberg J. 1973. Comparisons of canid and felid social systems from an evolutionary perspective. Animal Behaviour 21: 637-659.

Kleiman DG. 1977. Monogamy in mammals. Quarterly Review of Biology: 39-69.

Kleiman DG, Malcolm JR. 1981. The evolution of male parental investment in mammals. In, Parental care in mammals. Springer. pp. 347-387 
Knapp R, Wingfield JC, Bass AH. 1999. Steroid hormones and paternal care in the plainfin midshipman fish (Porichthys notatus). Hormones and Behavior 35: 81-89.

Kutsukake N, Clutton-Brock TH. 2010. Grooming and the value of social relationships in cooperatively breeding meerkats. Animal Behaviour 79: 271-279.

Lamprecht J. 1979. Field observations on the behaviour and social system of the bat-eared fox Otocyon megalotis Desmarest. Zeitschrift für Tierpsychologie 49: 260-284.

le Roux A, Cherry MI, Manser MB. 2008. The effects of population density and sociality on scent marking in the yellow mongoose. Journal of Zoology 275: 33-40.

le Roux A, Beishuizen R, Brekelmans W, Ganswindt A, Paris M, Dalerum F. 2014. Innovative parental care in a myrmecophageous mammal. Acta Ethologica 17: 63-66.

Logan C, Longino J. 2013. Adult male coatis play with a band of juveniles. Brazilian Journal of Biology 73: 353-355.

Londoño GC, Muñoz NT. 2006. Reproduction, behaviour and biology of the Giant river otter Pteronura brasiliensis at Cali Zoo. International Zoo Yearbook 40: 360-371.

Lukas D, Clutton-Brock T. 2012. Cooperative breeding and monogamy in mammalian societies. Proceedings of the Royal Society of London B: Biological Sciences 279: 21512156.

Lynn SE. 2008. Behavioral insensitivity to testosterone: why and how does testosterone alter paternal and aggressive behavior in some avian species but not others? General and Comparative Endocrinology 157: 233-240.

Macdonald DW. 1983. The ecology of carnivore social behaviour. Nature 301: 379-384.

Marneweck D, Cameron EZ, Ganswindt A, Dalerum F. 2015. Behavioural and endocrine correlates to the aardwolf mating system. Mammalian Biology 80: 31-38.

Martínez A, Ramos G, Martínez-Torres M, Nicolás L, Carmona A, Cárdenas M, Luis J. 2015. Paternal behavior in the Mongolian gerbil (Meriones unguiculatus): Estrogenic and androgenic regulation. Hormones and Behavior 71: 91-95.

McLeod PJ, Moger WH, Ryon J, Gadbois S, Fentress J. 1996. The relation between urinary cortisol levels and social behaviour in captive timber wolves. Canadian Journal of Zoology 74: 209-216.

Mech LD. 1999. Alpha status, dominance, and division of labor in wolf packs. Canadian Journal of Zoology 77: 1196-1203.

Mech LD. 2000. Leadership in wolf, Canis lupus, packs. Canadian Field-Naturalist 114: 259263.

Mech LD, Wolf PC, Packard JM. 1999. Regurgitative food transfer among wild wolves. Canadian Journal of Zoology 77: 1192-1195. 
Millspaugh JJ, Woods RJ, Hunt KE, Raedeke KJ, Brundige GC, Washburn BE, Wasser SK. 2001. Fecal glucocorticoid assays and the physiological stress response in elk. Wildlife Society Bulletin: 899-907.

Minter L, DeLiberto T. 2008. Seasonal variation in serum testosterone, testicular volume, and semen characteristics in the coyote (Canis latrans). Theriogenology 69: 946-952.

Moehlman PD. 1987. Social organization in jackals: the complex social system of jackals allows the successful rearing of very dependent young. American Scientist: 366-375.

Møller AP, Cuervo JJ. 2000. The evolution of paternity and paternal care in birds. Behavioral Ecology 11: 472-485.

Monder C, Sakai RR, Miroff Y, Blanchard DC, Blanchard RJ. 1994. Reciprocal changes in plasma corticosterone and testosterone in stressed male rats maintained in a visible burrow system: evidence for a mediating role of testicular 11 beta-hydroxysteroid dehydrogenase. Endocrinology 134: 1193-1198.

Monfort S, Mashburn K, Brewer B, Creel S. 1998. Evaluating adrenal activity in African wild dogs (Lycaon pictus) by fecal corticosteroid analysis. Journal of Zoo and Wildlife Medicine: 129-133.

Moss AM, Clutton-Brock T, Monfort S. 2001. Longitudinal gonadal steroid excretion in freeliving male and female meerkats (Suricata suricatta). General and Comparative Endocrinology 122: 158-171.

Müller CA, Manser MB. 2007. 'Nasty neighbours' rather than 'dear enemies' in a social carnivore. Proceedings of the Royal Society of London B: Biological Sciences 274: 959965.

Nelson RJ. 2005. An introduction to behavioral endocrinology, 4 ed. Sinauer Associates, Inc, Massachusetts.

Nichols HJ, Amos W, Bell MB, Mwanguhya F, Kyabulima S, Cant MA. 2012. Food availability shapes patterns of helping effort in a cooperative mongoose. Animal Behaviour 83: 1377-1385.

Nowak R, Porter RH, Lévy F, Orgeur P, Schaal B. 2000. Role of mother-young interactions in the survival of offspring in domestic mammals. Reviews of Reproduction 5: 153-163.

Nunes S, Fite JE, French JA. 2000. Variation in steroid hormones associated with infant care behaviour and experience in male marmosets (Callithrix kuhlii). Animal Behaviour 60: 857865.

Nunes S, Fite JE, Patera KJ, French JA. 2001. Interactions among paternal behavior, steroid hormones, and parental experience in male marmosets (Callithrix kuhlii). Hormones and Behavior 39: 70-82.

Pal S. 2005. Parental care in free-ranging dogs, Canis familiaris. Applied Animal Behaviour Science 90: 31-47. 
Páll MK, Mayer I, Borg B. 2002. Androgen and behavior in the male three-spined stickleback, Gasterosteus aculeatus: II. Castration and 11-ketoandrostenedione effects on courtship and parental care during the nesting cycle. Hormones and Behavior 42: 337-344.

Pauw A. 2000. Parental care in a polygynous group of bat-eared foxes, Otocyon megalotis (Carnivora: Canidae). African Zoology 35: 139-145.

Preston B, Stevenson I, Pemberton J, Coltman D, Wilson K. 2003. Overt and covert competition in a promiscuous mammal: the importance of weaponry and testes size to male reproductive success. Proceedings of the Royal Society of London B: Biological Sciences 270: 633-640.

Queller DC. 1997. Why do females care more than males? Proceedings of the Royal Society of London B: Biological Sciences 264: 1555-1557.

Rafacz ML, Margulis S, Santymire RM. 2012. Hormonal correlates of paternal care differences in the Hylobatidae. American Journal of Primatology 74: 247-260.

Richardson P. 1987. Aardwolf mating system-overt cuckoldry in an apparently monogamous mammal. South African Journal of Science 83: 405-410.

Richardson P, Coetzee M. 1988. Mate desertion in response to female promiscuity in the socially monogamous aardwolf Proteles cristatus. South African Journal of Zoology 23: 306-308.

Ridley M. 1978. Paternal care. Animal Behaviour 26: 904-932.

Robbins MM, Czekala NM. 1997. A preliminary investigation of urinary testosterone and cortisol levels in wild male mountain gorillas. American Journal of Primatology 43: 51-64.

Rood J. 1978. Dwarf mongoose helpers at the den. Zeitschrift für Tierpsychologie 48: 277287.

Rosas FCW, Cabral MMM, De Mattos GE, Silva RE. 2009. Parental and alloparental care of giant otters (Pteronura brasiliensis)(Carnivora, Mustelidae) in Balbina hydroelectric lake, Amazonas, Brazil. Sociobiology 54: 1-6.

Rosenblatt JS. 2002. Hormonal bases of parenting in mammals. In: Bornstein MH (ed), Handbook of Parenting: Biology and Ecology of Parenting. New Jersey: Lawrence Erlbaum Associates. pp. 31-60

Saltzman W, Ziegler T. 2014. Functional significance of hormonal changes in mammalian fathers. Journal of Neuroendocrinology 26: 685-696.

Sands J, Creel S. 2004. Social dominance, aggression and faecal glucocorticoid levels in a wild population of wolves, Canis lupus. Animal Behaviour 67: 387-396.

Schneider J, Lamprecht J. 1990. The importance of biparental care in a precocial, monogamous bird, the bar-headed goose (Anser indicus). Behavioral Ecology and Sociobiology 27: 415-419. 
Schwarzenberger F. 2007. The many uses of non-invasive faecal steroid monitoring in zoo and wildlife species. International Zoo Yearbook 41: 52-74.

Sharpe LL. 2005. Play does not enhance social cohesion in a cooperative mammal. Animal Behaviour 70: 551-558.

Sillero-Zubiri C, Gottelli D, Macdonald DW. 1996. Male philopatry, extra-pack copulations and inbreeding avoidance in Ethiopian wolves (Canis simensis). Behavioral Ecology and Sociobiology 38: 331-340.

Sillero-Zubiri C, Macdonald DW. 1998. Scent-marking and territorial behaviour of Ethiopian wolves Canis simensis. Journal of Zoology 245: 351-361.

Smith C, Wootton RJ. 1995. The costs of parental care in teleost fishes. Reviews in Fish Biology and Fisheries 5: 7-22.

Spinka M, Newberry RC, Bekoff M. 2001. Mammalian play: training for the unexpected. Quarterly Review of Biology: 141-168.

Strier KB, Ziegler TE, Wittwer DJ. 1999. Seasonal and social correlates of fecal testosterone and cortisol levels in wild male muriquis (Brachyteles arachnoides). Hormones and Behavior 35: 125-134.

Thornton A. 2008. Variation in contributions to teaching by meerkats. Proceedings of the Royal Society of London B: Biological Sciences 275: 1745-1751.

Thornton A, McAuliffe K. 2006. Teaching in wild meerkats. Science 313: 227-229.

Tilbrook A, Turner A, Clarke I. 2000. Effects of stress on reproduction in non-rodent mammals: the role of glucocorticoids and sex differences. Reviews of Reproduction 5: 105113.

Townsend DS, Moger WH. 1987. Plasma androgen levels during male parental care in a tropical frog (Eleutherodactylus). Hormones and Behavior 21: 93-99.

Trainor BC, Marler CA. 2001. Testosterone, paternal behavior, and aggression in the monogamous California mouse (Peromyscus californicus). Hormones and Behavior 40: 3242.

Trivers R. 1972. Parental investment and sexual selection. Biological Laboratories, Harvard University.

van Kesteren F, Sillero-Zubiri C, Millar R, Argaw K, Macdonald DW, Paris M. 2012. Sex, stress and social status: patterns in fecal testosterone and glucocorticoid metabolites in male Ethiopian wolves. General and Comparative Endocrinology 179: 30-37.

Viau V, Meaney MJ. 2004. Testosterone-dependent variations in plasma and intrapituitary corticosteroid binding globulin and stress hypothalamic-pituitary-adrenal activity in the male rat. Journal of Endocrinology 181: 223-231. 
Wingfield JC, Hegner RE, Dufty Jr AM, Ball GF. 1990. The" challenge hypothesis": theoretical implications for patterns of testosterone secretion, mating systems, and breeding strategies. The American Naturalist: 829-846.

Woodroffe R, Vincent A. 1994. Mother's little helpers: patterns of male care in mammals. Trends in Ecology \& Evolution 9: 294-297.

Woodroffe R, Macdonald D, Silva J. 1995. Dispersal and philopatry in the European badger, Meles meles. Journal of Zoology 237: 227-239.

Woodroffe R, Macdonald D, Cheeseman C. 1997. Endocrine correlates of contrasting male mating strategies in the European badger (Meles meles). Journal of Zoology 241: 291-300.

Wright HW, Gray MM, Wayne RK, Woodroffe RB. 2010. Mating tactics and paternity in a socially monogamous canid, the bat-eared fox (Otocyon megalotis). Journal of Mammalogy 91: 437-446.

Wright HWY. 2006. Paternal den attendance is the best predictor of offspring survival in the socially monogamous bat-eared fox. Animal Behaviour 71: 503-510.

Wright PC. 1990. Patterns of paternal care in primates. International Journal of Primatology 11: 89-102.

Wynne-Edwards KE, Reburn CJ. 2000. Behavioral endocrinology of mammalian fatherhood. Trends in Ecology \& Evolution 15: 464-468.

Young AJ, Spong G, Clutton-Brock T. 2007. Subordinate male meerkats prospect for extragroup paternity: alternative reproductive tactics in a cooperative mammal. Proceedings of the Royal Society of London B: Biological Sciences 274: 1603-1609.

Young K, Walker S, Lanthier C, Waddell W, Monfort S, Brown J. 2004. Noninvasive monitoring of adrenocortical activity in carnivores by fecal glucocorticoid analyses. General and Comparative Endocrinology 137: 148-165.

Zarrow M, Gandelman R, Denenberg V. 1971. Prolactin: Is it an essential hormone for maternal behavior in the mammal? Hormones and Behavior 2: 343-354.

Zav'ialov E, Gerlinskaia L, Moshkin M. 2012. Factors of stress in a local population of water vole. Zhurnal obshchei biologii 73: 59-69.

Ziegler TE, Snowdon CT. 2000. Preparental hormone levels and parenting experience in male cotton-top tamarins, Saguinus oedipus. Hormones and Behavior 38: 159-167.

Ziegler TE, Washabaugh KF, Snowdon CT. 2004. Responsiveness of expectant male cotton-top tamarins, Saguinus oedipus, to mate's pregnancy. Hormones and Behavior 45: 84-92.

Zielinski WJ, Vandenbergh JG. 1993. Testosterone and competitive ability in male house mice, Mus musculus: laboratory and field studies. Animal Behaviour 45: 873-891. 